\title{
The Moderating Effects of Self-Efficacy on the Relationship Between Personality Traits (Extraversion, Neuroticism, Agreeableness, Openness, and Conscientiousness) and Cigarette Smoking Behavior Among Adolescents in Kerman, Iran
}

\author{
Samira Golestan ${ }^{1}$, Hanina, H. Hamsan ${ }^{2} \&$ Haslinda Binti Abdullah ${ }^{3}$ \\ ${ }^{1}$ Faculty of Human Ecology, University Putra Malaysia, E-11-02, The Heritage, Mines Resort City, 43300 \\ Seri Kembangan, Selangor, Malaysia \\ ${ }^{2}$ Department of Social and Development Science, Faculty of Human Ecology, University Putra Malaysia, 43400 \\ Serdang, Selangor, Malaysia \\ ${ }^{3}$ Institute for Social Science Studies (IPSAS), University Putra Malaysia, UPM Serdang, Selangor, 43400, \\ Malaysia \\ Correspondence: Samira Golestan, Faculty of Human Ecology, University Putra Malaysia, E-11-02, The Heritage, \\ Mines Resort City, 43300 Seri Kembangan, Selangor, Malaysia. Tel: 98-913-343-6185 E-mail: \\ samira_golestan@yahoo.com
}

Received: August 4, 2014 Accepted: August 17, 2014 Online Published: November 10, 2014

doi:10.5539/ach.v7n1p187 URL: http://dx.doi.org/10.5539/ach.v7n1p187

\begin{abstract}
This paper aims to examine the relationship between personality traits (extraversion, neuroticism, agreeableness, openness, and conscientiousness) and cigarette smoking behavior and also determine the moderating effect of self-efficacy on the relationship between personality traits and cigarette smoking behavior among adolescents in Kerman, Iran. A quantitative research method was employed. The samples included three hundred current smoker adolescents between the ages of 15 to 18 . The data was collected by means of self-administered questionnaires and then analyzed by AMOS software. The direct structural model was employed to figure out the path relationships between personality traits (extraversion, neuroticism, agreeableness, openness, and conscientiousness) and cigarette smoking behavior. In addition, a multi-group analysis approach was applied to assess the moderating effect of self-efficacy on the relationship between personality traits (extraversion, neuroticism, agreeableness, openness, and conscientiousness) and cigarette smoking behavior among adolescents. The results of testing the structural equation model showed that there were significant relationships between personality traits (neuroticism and conscientiousness) and cigarette smoking behavior whereas there was no significant relationship between personality traits (extraversion, agreeableness and openness) and cigarette smoking behavior. Also, the results related to the moderating effect of self-efficacy revealed that self-efficacy significantly moderated the effect of neuroticism on cigarette smoking behavior but did not moderate the relationship of other personality traits i.e. extraversion, openness, agreeableness and conscientiousness with and cigarette smoking behavior. At the end, this study recommends some solutions in order to prevent cigarette smoking behavior among adolescents.
\end{abstract}

Keywords: personality traits, cigarette smoking behavior, self-efficacy, adolescents

\section{Introduction}

Cigarette smoking has been identified as a major public health problem worldwide (Eftekhari, Nassr \& Sallehi, 2007; Sarafzade, Boshtam, \& Tafazoli, 2004). It is a widely known risk factor for the development of cardiovascular diseases, chronic obstructive pulmonary diseases, and lung cancer, which are all associated with increased mortality rates (Berkow, Beers, \& Fletcher, 2000; Deborah, 2006). Also, cigarette smoking contributes to chronic illnesses that decrease the quality of life and result in less productivity (Nichols, 2006). In addition, smoking has been found to correlate with the use of other substances, including alcohol and drugs that can have additional negative consequences (Deborah, 2006; Junger, Stroebe, \& Laan, 2001). Smoking is the sixth cause of 
death in the world and if the trend remains the same until 2030, the number of smoking-induced deaths will increase to eight to ten million (World Health Organization, 2008).

Initiation of cigarette smoking occurs almost exclusively during adolescence (Burns \& Pierce, 1997; Poorasl, Fakhari, \& Shamsipour, 2011; Ziaaddini, meymandi, \& Zarezadeh, 2007). Many international studies have shown that about 85 to $90 \%$ of heavy smokers start smoking before the age of 20.They also indicated that smoking in adolescence is a strong predictor of smoking in adulthood (Mohammadpoor, Fakhari, \& Rostami, 2007; Taioli \& Wynder, 1991). Smoking just a few cigarettes during adolescence leads to a 16 -fold increase of the risk of adult smoking (Mohammadpoor et al., 2007). Furthermore, the earlier one starts smoking, the more cigarettes per day one will smoke as an adult. Therefore, adolescent cigarette smoking is of a great significance for public health.

Cigarette consumption has been increasing in most developing countries during the past 20 years. The World Health Organization has described smoking as an epidemic in developing countries (Rozi, Butt, \& Akhtar, 2007; World Health Organization, 2008). There are about 1.3 billion smokers in the world and approximately $80 \%$ of them live in the developing countries (American Cancer Society, 2006; Rozi et al., 2007).

Among developing countries, Iran has one of the youngest population profiles in the world (Ziaaddini et al., 2007; pouresmlami, 2008). Approximately, $71 \%$ of Iranian smokers reported that their first smoking experience was in their adolescence (Kelishadi, Ardalan, \& Gheiratmand, 2006; Pouresmlami, 2008; Ziaaddini et al., 2007). Kerman is one of the major urban areas in the central part of Iran. This province is well-known for its major social problem, i.e. the prevalence of cigarette smoking among adolescents (Nakhaee \& Divsalar, 2009; Ziaaddini et al., 2007). Currently, the consumption of cigarette is very common among adolescents in Kerman (Ziaaddini, meymandi, \& Zarezadeh, 2007). Research shows that in Kerman the average age of smoking initiation is $15.9 \pm 4.5$ years and the age of starting smoking in $48.35 \%$ of smokers is before 20 (Nakhaee \& Divsalar, 2009).

Albeit a vast number of attempts to prevent or decrease smoking behavior, this habit is still increasingly prevalent among young people in Iran. Even in comparison with developed countries the number of adolescent smokers in Iran is relatively higher and indicates an increasing trend (Poorasl et al., 2011).

As adolescent smoking is considered to be a gateway to the use of alcohol and other illicit drugs, researchers are challenged to develop proper solutions and provide the communities with recommendations in this regard.

In the light of previous findings, personality traits (extraversion, neuroticism, agreeableness, openness, and conscientiousness) and self-efficacy are posited to play a role in cigarette smoking behavior.

Stable and peculiar personality traits of each individual (neuroticism, extraversion, openness, agreeableness, and conscientiousness) can explain the variability in health perceptions and are regarded as risk factors underlying cigarette smoking and other drugs abuse (Ebert et al., 2002; Terracciano, Lockenhoff, Crum, Bienvenu, \& Costa, 2008). Based on the personality traits of the individuals, their tendency toward initiating and continuing smoking can be determined (Diane et al., 2005; Zargar \& Ghafari, 2009; Torres \& Pritchard, 2005).

Also, self-efficacy is significantly associated with cigarette smoking among adolescents and increases the likelihood of cigarette smoking behavior (Hiemstra et al., 2011). Researchers have demonstrated that the effect of self-efficacy on behavior is pervasive and that self-efficacy influences the problematic behaviors like cigarette smoking (Diane et al., 2005; Fagan et al., 2003; Hiemstra, Otton, De Leeuw, Schayck, \& Engels, 2011; Von, Ebert, Ngamvitroj, Park, \& kang, 2005). They suggest that cigarette smoking behavior is significantly associated with the level of self-efficacy. The outcomes of a number of studies revealed that those who smoked more cigarettes had lower self-efficacy scores and were less confident in their ability to avoid smoking than those who smoked less (Ehrhart, 2005; Fagan et al., 2003; Sterling et al., 2007).

Although self-efficacy has been found to be directly related to cigarette smoking among adolescents, few studies have examined whether higher self-efficacy acts as a moderator to change the effect of influencing factors on cigarette smoking behavior. Even though a great deal has been learned about the prediction of adolescent smoking by the influence of a lot of factors, not enough attention has been paid to how these constructs may interact with moderator variables.

Thus, in order to fill the research gap, in the present study the interactive effects of a moderating variable (self-efficacy) with personality traits (extraversion, neuroticism, agreeableness, openness, and conscientiousness) influence on adolescent smoking behavior will be examined in a sample of smokers' adolescents. In fact, no research has "so far examined the moderating effects of self-efficacy in the process of personality traits (extraversion, neuroticism, agreeableness, openness, and conscientiousness) and cigarette smoking behavior among adolescents. 
Therefore, the present study was proposed to examine relationship between personality traits (extraversion, neuroticism, agreeableness, openness, and conscientiousness) and cigarette smoking behavior and also investigate the moderating effects of self-efficacy on the relationship between personality traits (extraversion, neuroticism, agreeableness, openness, and conscientiousness) and cigarette smoking behavior among adolescents in Kerman, Iran.

\section{Methodology}

\subsection{Sample Procedure and Sample Profile}

The study sample comprises adolescents' cigarette smoker between the ages of 15 to 18 in high schools in Kerman. Twenty-two schools were selected for the study using a cluster sampling technique. In order to determine the sample size, G-Power statistical analysis program developed by Erdfelder, Faul and Buchner (1996) was used. After setting the values of .1 for effect size, a power of .95 and alpha .05 , the regression was selected as the data analysis method. The sample size, calculated by the software as the most suitable for this method, was 300 .

\subsection{Instrumentation}

Personality traits scale: NEO-PI-R 60-item personality inventory, for measuring the Big Five personality dimensions, asserts that the following five factors, namely neuroticism, extraversion, openness, conscientiousness and agreeableness, can describe most personality traits. The 60 items in this section were adapted from Costa and McCrae (1992). NEO-PI-R inventory was rated on a five-point Likert scale, which ranged from $0=$ strongly disagree, to $4=$ strongly agree.

Self-Efficacy Scale: Self-efficacy was measured by the eight-item adapted from the Smoking Self-Efficacy Questionnaire (Etter, Bergman, Humair, \& Perneger, 2000). This instrument had a five-point Likert-type scale (Not at all sure (1) to absolutely sure (5)). The highest score indicated a high level of self-efficacy and the lowest score indicated a low level of self-efficacy.

Cigarette Smoking Behavior Scale: Cigarette smoking behavior was measured with questions refined from the national high school YRBS questionnaire (Centers for Disease Control and Prevention, 2000). This scale is a 5-item self report questionnaire designed to measure cigarette smoking behavior and rated on a seven-point Likert scale. 'Smoked 10-30 days in the past 30' and 'smoked less than five cigarettes each day' means light current smoker. 'Smoked 10-30 days in the past 30' and 'smoked five or more cigarettes each day' means heavy current 'smoker and smoked 1-9 days in the past 30' means occasional current smoker.

\section{Results and Discussion}

\subsection{Descriptive Statistics}

Table 1. Frequencies and Percentages of Respondents’ Demographic Background

\begin{tabular}{lll}
\hline Variables & Number $(\mathrm{N}=300)$ & Percentage $(\%)$ \\
\hline Age $(\mathrm{n}=300)$ & 69 & 23.0 \\
15 years & 72 & 24.0 \\
16 years & 80 & 26.7 \\
17 years & 79 & 26.3 \\
18 years & & \\
$\quad$ Mean=16.5 & 69 & 23.0 \\
Level of Education & 72 & 24.0 \\
$\quad$ First grade & 80 & 26.7 \\
$\quad$ Second grade & 79 & 26.3 \\
Third grade & & \\
$\quad$ Pre-university & 195 & 65.0 \\
Gender & 35 & 35.0 \\
Male & & \\
Female & 199 & 66.3 \\
Monthly Pocket Money(Thousand Toman) & 101 & 33.7 \\
$\quad<130$ & & \\
$\quad>130$ & &
\end{tabular}


The descriptive analyses of the respondents' demographic background namely age, gender, level of education, monthly pocket money are presented in Table 1. This Table shows the frequencies and percentages of respondents' demographic background.

The age of the 300 study adolescents, as reported by the respondents, ranged from 15 to 18 . Their mean age was 16.5. The Majority of the respondents (53\%) belonged to the age group of $17-18$ year-olds. Regarding gender, $65 \%$ of the adolescents were male and $35 \%$ were female. In terms of education, the largest part of the subjects in this study belonged to the third grade; that comprised $26.7 \%$ of the whole subjects. Also, Table 1 illustrates that the majority of the respondent's (66.3\%) monthly pocket money has been between $0-130$ thousand Tomans (almost 50 dollars).

\subsection{The Inferential/Structural Equation Modeling (SEM) Results}

The multivariate technique of Structural Equation Modeling was employed to test the validity of the instrument, based on the collected data and its underline research hypothesis. In this section the results are presented in three phases based on the practical step in SEM analyses. These includes: first, Individual Confirmatory Factor Analysis for each latent variable; second, the measurement model or overall CFA model which comprises the latent variables in the study, and third, the structural models to test the research hypotheses.

\subsubsection{The Confirmatory Factor Analysis Models}

Prior to start the Structural Equation Modeling, it is necessary to confirm the study constructs individually in terms of their model fit and convergent validity.

\subsubsection{Personality Traits Individual CFA}

The studied personality traits include extraversion, conscientiousness, neuroticism, agreeableness, and openness. They have been measured using a standardized scale through 60 items in which each trait is deliberated by 12 items. The individual CFA of Personality Traits' construct has been specified. In fact, the results reveal that the CFA model fit the data. The Figure 1 demonstrates the goodness of fit indices; they all have the acceptable value for presenting a good fit including: [Relative $\chi 2=1.309 ; \mathrm{CFI}=.950, \mathrm{IFI}=.950, \mathrm{TLI}=.948, \mathrm{RMSEA}=.032$ ] except $\mathrm{GFI}=.800$ and $\chi^{2}(1700)=2224.728, \mathrm{p}=.000$. According to Hair et al. (2006), if three to four indices meet the criteria, it offers adequate evidence of model fit. Thus, the investigation of the goodness of fit indices five index supports a good fit for the model. After specification of Individual CFA and monitoring the goodness of fit indices for the model fit, the validity of individual CFA was investigated. To conduct the validity assessment of construct, it is necessary to assess the factor loadings, average variance extracted, and construct reliability. Table 2 shows (Appendix A), the results of validity assessment for the Personality Traits construct. The results confirm that all the items have adequate standardized factor loading ranging from .623 to .811 to support the construct validity. The investigation of the second criteria of construct validity which is average variance extracted, also supports and confirms the validity of Personality Traits construct as the AVE's value exceeded the cutoff point of .5 although the Neuroticism AVE value was .48 which is too close and ignorable. The third and last indictor of construct validity is construct reliability. Assessment of construct reliability determined the Personality Traits constructs reliability in a very good level while the lowest construct reliability was belong to the Neuroticism the value of .91 showing very good reliability. Thus, the convergent validity of Personality Traits construct has been confirmed. The results of this assessment confirmed that the Personality Traits construct has been measured using valid and reliable items for each trait.

\subsubsection{Self-Efficacy Individual CFA}

The self-efficacy construct was measured using eight items. Using the determined items the individual CFA model has been specified. The model is portrayed in figure 2. The first step to investigate a construct is to assess the model fit using goodness of fit indices. The results of model fit assessment for the self-efficacy construct supports that the model fits the data according to the following goodness of fit indices: Relative $\chi 2=2.772$; GFI $=.954$, CFI $=.973, \mathrm{IFI}=.973, \mathrm{TLI}=.963, \mathrm{RMSEA}=.077 \mathrm{except}$ chi-Square $(\chi 2(20)=55.440, \mathrm{p}=.000)$. The reason has been discussed in pervious individual CFA. Consequently, it could be said that goodness of fit indices support a good fit for model.

The second step of investigating a construct is to assess the convergent validity of construct through factor loadings, average variance extracted, and construct reliability. The results of convergent validity assessment are reported in table 3. The results are as follows: the standardize factor loading for the self-efficacy construct is ranging from .697 to .853 ; they all get the acceptable value and fall between the acceptable range and exceed the cutoff point of .5. The average variance extracted for the self-efficacy construct was .57 and was satisfied as its goes beyond the required value of .5 . The calculation of construct reliability for the self-efficacy construct resulted 
in value of .91 that is in an acceptable and good level and further exceeds the acceptable value of .7. Consequently, the convergent validity for the self-efficacy construct was confirmed through assessment of three indicators including standardize factor loading, average variance extracted, and construct reliability. Additionally, it could be said that the self-efficacy construct in this study has been measured through valid and reliable items.

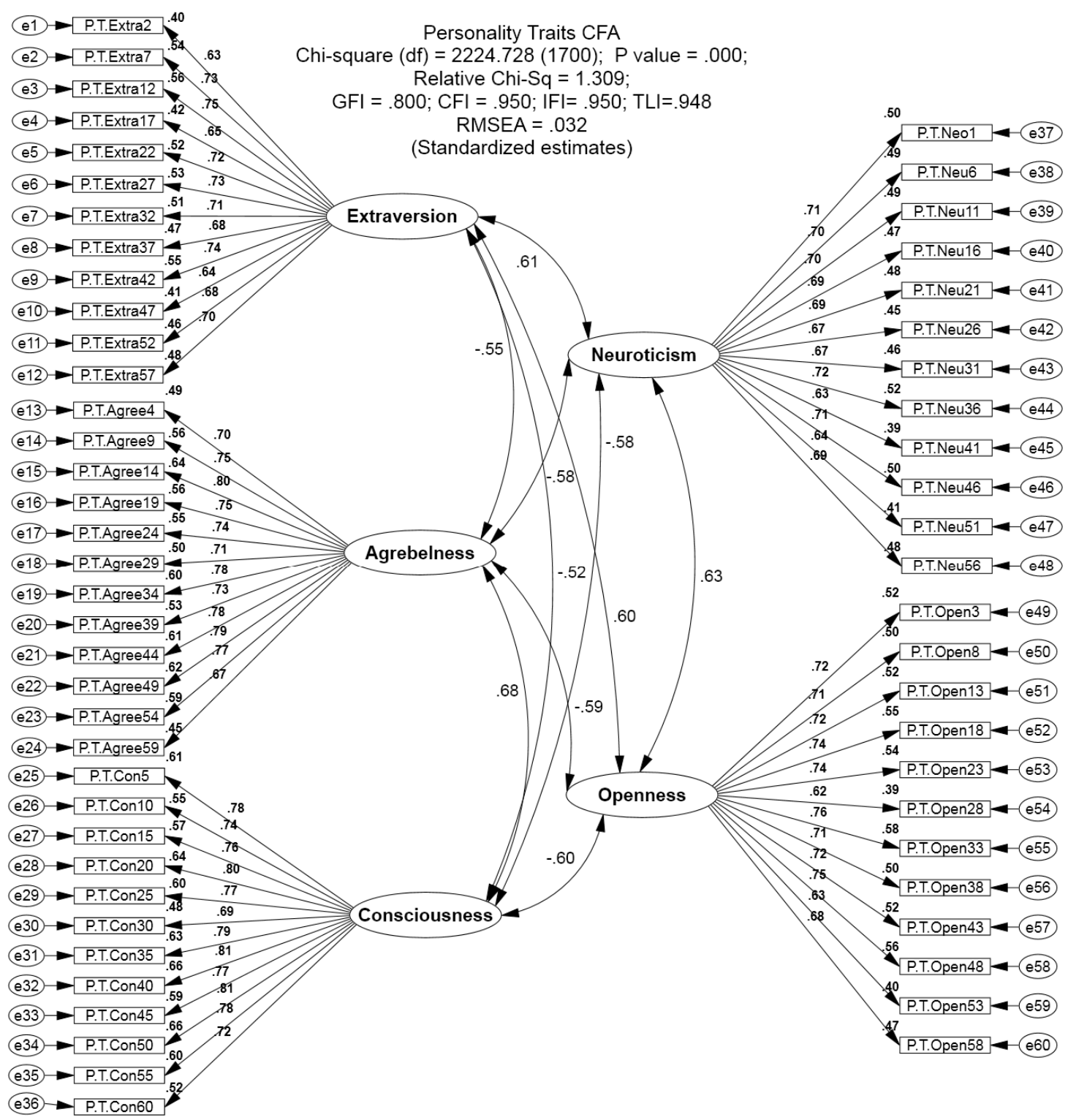

Figure 1. Personality Traits CFA Model 


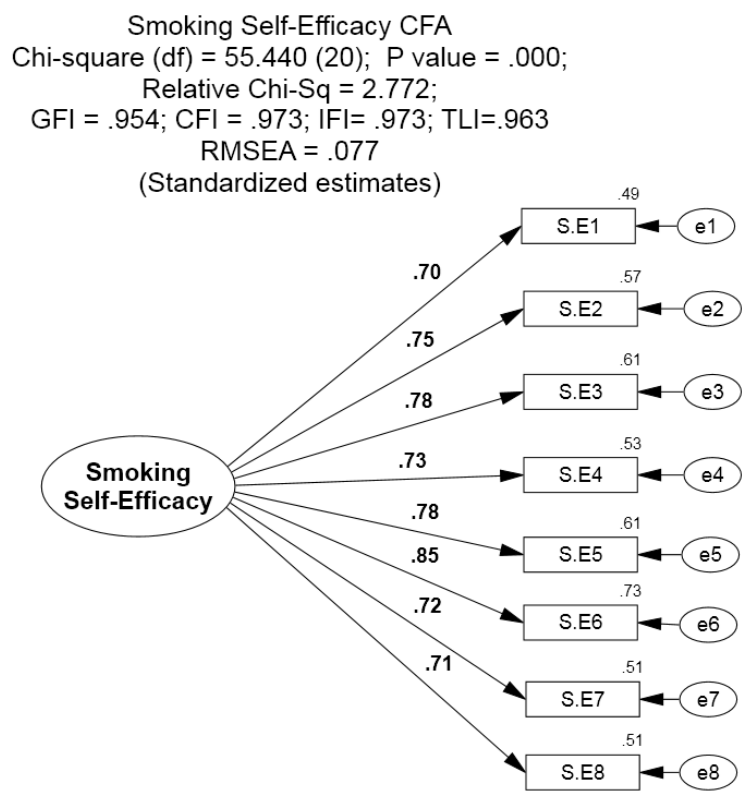

Figure 2. Self-Efficacy CFA Model

Table 3. The Result of Self-Efficacy CFA Model

\begin{tabular}{ccccc}
\hline Variable/dimension & Items & $\begin{array}{c}\text { Standardized } \\
\text { Factor loading }\end{array}$ & $\begin{array}{c}\text { Average Variance Extracted } \\
\text { (AVE) }\end{array}$ & $\begin{array}{c}\text { Construct Reliability } \\
(\mathrm{CR})\end{array}$ \\
\hline & S.E1 & .697 & & \\
& S.E2 & .752 & & \\
& S.E3 & .780 & .57 & .91 \\
Self-Efficacy & S.E4 & .726 & & \\
& S.E5 & .779 & & \\
& S.E6 & .853 & & \\
& S.E7 & .717 & & \\
& S.E8 & .711 & & \\
\hline
\end{tabular}

\subsubsection{The Structural Equation Model}

After specifying the individual CFA and the measurement model of study (to test the validity of the instrument based on collected data), the structural model of the study was designed. The direct structural model was employed to test the hypothesized path relationships between the variables based on the conceptual research framework.

$\mathrm{H}_{\mathrm{A1}}$ : There is a significant relationship between personality traits (neuroticism, extraversion, openness, agreeableness, and conscientiousness) and cigarette smoking behavior among adolescents in Kerman.

The result, as displayed in Table 4 , show that there is no significant relationship between extraversion $(\beta=.049$, C. $R=1.493, P=.135)$, agreeableness $(\beta=-.052, C . R=-1.146, P=.252)$ and openness $(\beta=.001, C . R=.039, P=.969)$ with cigarette smoking behavior. The result indicated a positive significant relationship between neuroticism personality trait $(\beta=.080, C . R=2.263, P=.024)$ and a negative significant relationship between conscientiousness personality traits $(\beta=-.118, C . R=-2.937, \mathrm{P}=.003)$ and cigarette smoking behavior. As a result, among these five personality traits, the relationship between neuroticism and conscientiousness personality trait and cigarette smoking behavior was confirmed. 
Table 4. Regression Weights based on the Structural Model

\begin{tabular}{cccccccc}
\hline \multicolumn{2}{c}{ Path hypothesis } & \multicolumn{2}{c}{ Estimate } & S.E. & $\begin{array}{c}\text { Standardized Regression } \\
\text { Weights }\end{array}$ & C.R. & P \\
\hline Extraversion & $\rightarrow$ & $\begin{array}{c}\text { Cigarette Smoking } \\
\text { Behavior }\end{array}$ & .170 & .114 & .049 & 1.493 & .135 \\
Neuroticism & $\rightarrow$ & $\begin{array}{c}\text { Cigarette Smoking } \\
\text { Behavior }\end{array}$ & .259 & .115 & .080 & 2.263 & .024 \\
Openness & $\rightarrow$ & $\begin{array}{c}\text { Cigarette Smoking } \\
\text { Behavior }\end{array}$ & .005 & .124 & .001 & .039 & .969 \\
Agreeableness & $\rightarrow$ & $\begin{array}{c}\text { Cigarette Smoking } \\
\text { Behavior }\end{array}$ \\
Conscientiousness & $\rightarrow$ & -.159 & .139 & -.052 & -1.146 & .252 \\
\hline
\end{tabular}

\subsubsection{Test of the Moderating Hypothesis (Self-Efficacy)}

As presented in the above section for individual CFAs, self-efficacy in this study was measured as latent variable through 8 item/indicators. In order to test the moderating effects of self-efficacy it was necessary to recode and categorized this variable in two levels including low and high self-efficacy respondent. For this purpose, first the eight items (as the all of them validate based on CFA model for this variable) were computed, and then the mean was calculated. Finally based on the mean score the respondents were divided in to two groups.

In order to test moderating effects of self-efficacy as main specific objective of this study on the path relationship between the variable, the advance technique of multi-group Structural Equation Modeling analysis was employed. The multi-group analysis technique by using AMOS software, the system produced two variant/unconstrained and invariant/equal group models (Hair et al., 2006, 2010). According to unconstrained group model hypothesized to have a different regression weights for low and high self efficacy respondent, whereas based on invariant group model, it is estimated that the path relationships of interest is constrained to be equal among respondents with low and high self efficacy.

$\mathrm{H}_{\mathrm{A} 2}$ : Self-efficacy moderating effects on the path relationships between the personality traits (neuroticism, extraversion, openness, agreeableness and conscientiousness) and cigarette smoking behavior

According to the above mentioned rule the results show that the path relation between the extraversion, openness, agreeableness and conscientiousness personality traits with cigarette smoking behavior in both groups (low and high self-efficacy) was not significant. Therefore, the moderating effect of self-efficacy on the path relation between these personality traits and cigarette smoking behavior was not supported (Table 5 and 6).

As the results depicted in table 5 and table 6 show the path relationship between neuroticism personality traits for respondents with low self-efficacy is significant $(\beta=.141, \mathrm{C} . \mathrm{R}=3.368, \mathrm{P}=.000)$ but for respondents with high self efficacy it is insignificant $(\beta=.080, \mathrm{C} . \mathrm{R}=1.187, \mathrm{P}=.235)$. Thus the moderating effect of self-efficacy on the path relation between neuroticism personality traits and cigarette smoking behavior is supported (table 5 and 6 ).

Table 5. Regression Weights based on Unconstrained Structural Model for Low Self-efficacy Respondent

\begin{tabular}{lllllllll}
\hline Path hypothesis & & & & Estimate & S.E. & $\begin{array}{l}\text { Standardized } \\
\text { Regression Weights }\end{array}$ & C.R. & P \\
\hline Extraversion & $\rightarrow$ & $\begin{array}{l}\text { Cigarette } \\
\text { Behavior }\end{array}$ & Smoking & .103 & .107 & .035 & .961 & .336 \\
Neuroticism & $\rightarrow \begin{array}{l}\text { Cigarette } \\
\text { Behavior }\end{array}$ & Smoking & .404 & .120 & .141 & 3.368 & .000 \\
Openness & $\rightarrow \begin{array}{l}\text { Cigarette } \\
\text { Behavior }\end{array}$ & Smoking & -.197 & .125 & -.059 & -1.566 & .117 \\
Agreeableness & $\rightarrow \begin{array}{l}\text { Cigarette Smoking } \\
\text { Behavior }\end{array}$ & -.182 & .136 & -.069 & -1.338 & .181 \\
Conscientiousness & $\rightarrow \begin{array}{l}\text { Cigarette } \\
\text { Behavior }\end{array}$ & Smoking & -.142 & .156 & -.039 & -.908 & .364 \\
\hline
\end{tabular}


Table 6. Regression Weights based on Unconstrained Structural Model for High Self-efficacy Respondent

\begin{tabular}{|c|c|c|c|c|c|c|c|}
\hline Path hypothesis & & Estimate & S.E. & & $\begin{array}{l}\text { Standardized } \\
\text { Regression Weights }\end{array}$ & C.R. & $\mathrm{P}$ \\
\hline Extraversion & $\rightarrow$ & Cigarette Smoking Behavior & -.143 & .380 & -.025 & -.375 & .707 \\
\hline Neuroticism & $\rightarrow$ & Cigarette Smoking Behavior & .286 & .241 & .080 & 1.187 & .235 \\
\hline Openness & $\rightarrow$ & Cigarette Smoking Behavior & .451 & .281 & .109 & 1.605 & .109 \\
\hline Agreeableness & $\rightarrow$ & Cigarette Smoking Behavior & -.535 & .381 & -.136 & -1.404 & .160 \\
\hline Conscientiousness & $\rightarrow$ & Cigarette Smoking Behavior & -.097 & .369 & -.022 & -.262 & .793 \\
\hline
\end{tabular}

\section{Discussion}

This study focused on the role of personality traits (extraversion, neuroticism, agreeableness, openness, and conscientiousness) and cigarette smoking behavior, and examined the moderating effect of self-efficacy on the relationship between personality traits (extraversion, neuroticism, agreeableness, openness, and conscientiousness) and cigarette smoking behavior among adolescents in Kerman.

The results showed that the two personality traits of neuroticism and conscientiousness were significantly related to cigarette smoking behavior while there were no significant relationship between other three personality traits, namely extraversion, agreeableness and openness. Neuroticism as a significant personality trait has been positively associated with cigarette smoking behavior. In other words, an increased level of neuroticism is related to higher levels of cigarette smoking behavior. Neuroticism involves emotional instability and encompasses a variety of negative emotions including anger and anxiety. Individuals with high neuroticism tend to be impulsive and anxious and are less likely to adhere to positive behavior. So, high scores on neuroticism could be a cause as well as an effect of cigarette smoking behavior. This finding supported research done by Diane et al. (2005), Terracciano et al. (2008) and Miller (2009) who suggested that high neuroticism is a risk factor for cigarette smoking behavior.

Also, conscientiousness as a second significant personality trait in this study was inversely related to cigarette smoking behavior. This means that a lower score on conscientiousness is associated with higher levels of cigarette smoking behavior. This finding supported research done by Diane et al. (2005), Hames and Parker (2008) and Zargar and Ghaffari (2009) that distinguished a significant negative relationship between personality trait (conscientiousness) and cigarette smoking behavior. They figured out a decreased level of conscientiousness associated with higher level of cigarette smoking behavior of the smokers. So, a lower level of conscientiousness is a risk factor for cigarette smoking behavior. The present findings also provided support for the Big Five Factor Model of Personality that emphasizes on the effect of personality traits (conscientiousness and neuroticism) on various problem behaviors such as smoking, alcohol, drug abuse.

However, the results of this study demonstrated that there were no significant relationship between the other three personality traits; i.e. extraversion, agreeableness and openness. Although, it had been expected that there were significant relationship between all personality traits and cigarette smoking behavior, in the outcomes of the present research showed no significant relationship. In fact, the findings of the previous studies on the association between extraversion, agreeableness and openness with cigarette smoking behavior were not the same and showed different results in different geographical contexts. For instance, in Australia, there were significant relationships between these personality traits and cigarette smoking behavior whereas in other countries such as Canada and the United States there were no significant relationships. It could be concluded that the variety of outcomes is originated from multiple factors like different educational programs, culture, and different environmental impacts. The findings of the present study in the context of Iran were consistent with Diane et al. (2005), Hames and Parker (2008) and Terracciano et al. (2008) who proved that there were no significant relationship between extraversion, agreeableness and openness and cigarette smoking behavior.

In addition, this study examined the moderating effects of self-efficacy on the relationship between personality traits (extraversion, neuroticism, agreeableness, openness, and conscientiousness) and cigarette smoking behaviour based on the advanced technique of multi-group Structural Equation Modeling. The findings regarding moderating effect of self-efficacy showed that self-efficacy moderated the relationship between personality traits of neuroticism and cigarette smoking behavior. However, it did not moderate the relationship between personality traits of openness, extraversion, conscientiousness and agreeableness and cigarette smoking behavior. 
One of the novelties and contribution of this study was to test the moderating effect of self-efficacy on the relationships between the personality traits (extraversion, neuroticism, agreeableness, openness, and conscientiousness) and cigarette smoking behavior among adolescents. In fact, previous studies have examined the direct relationship between self-efficacy and cigarette smoking behavior. But no research has examined the moderating effect of self-efficacy in the process of personality traits (extraversion, neuroticism, agreeableness, openness, and conscientiousness) and cigarette smoking behavior among adolescents.

\section{Conclusion and Implication}

The findings of the present study confirm that some personality traits (consciousness and neuroticism) effect cigarette smoking behavior of adolescents. Hence, there is a need to provide programs to address the personality dimensions (consciousness and neuroticism), consider individual treatment and assess their personality traits. Although individual treatment might reduce the rate of smoking, it can still rely only on the individual's resources and, thus, have limited results. This is because of the high impulsivity of the smokers and lack of consideration on the consequences of their actions. Even with full knowledge of the harmful effects of smoking, they may be unable to control their smoking. Thus, relying only on the individual's resources could be a poor strategy for preventing smoking. As a result, it is recommended that educators consider the public policy strategies as an effective tool to reduce cigarette smoking behavior. Some instances are creating societal pressure in form of high taxation, restricting the relevant advertisement, and forbidding smoking in public places. A combination of public policies and treatment strategies could be tailored to the needs of individual smokers in certain social contexts and consequently reduce the prevalence of cigarette smoking behavior. These programs are more cost effective than programs that rely only on the efforts of individual treatment in reducing the prevalence of cigarette smoking.

The results of this study also proved the moderating effect of self-efficacy on the relationship between personality trait of neuroticism and cigarette smoking behaviour among adolescents. The results showed that there was a stronger impact of personality trait of neuroticism on cigarette smoking behaviour in adolescents with low self-efficacy than in those with high self-efficacy on cigarette smoking behaviour. This implies that adolescents with higher self-efficacy are less affected on the negative behaviour such as cigarette smoking than the adolescents with lower self-efficacy. So, having a high level of self efficacy is effective in controlling negative behaviors like smoking. This makes the implications for educators even more obvious, given the important role of self-efficacy on the rate of cigarette smoking behaviour among adolescents. Self efficacy enables individuals to set their targets, to organize what they think and to take action. Individuals with high self-efficacy monitor their ideas, act in accordance with these ideas, evaluate the outcomes of their behaviors and change them accordingly when necessary. In other words, adolescents with a high level of self efficacy are able to cope with problems in a better way and are less likely to display negative behaviors such as smoking. They start and continue to smoke less than adolescents with a low level of self efficacy. Therefore, it is important that educators provide programmes to enhance self-efficacy. The prevention programs focused on self-efficacy may be an effective way for reducing the frequency, initiation and amount of cigarette smoking among adolescents.

In addition, to reduce adolescents smoking rates, it is recommended that policy makers present anti-smoking programs through media (such as billboard, advertising, radio, internet, newspaper, TV, etc), publications (public education materials), training program for skill development, on-site consultation, booklets and pamphlets for knowledge enhancement about smoking. In addition, they should conceptualize and offer programs for raising the public awareness on health. Passing laws in order to restrict cigarette smoking (e.g. ban of cigarette smoking in public spaces) is also another way to fight smoking. However, one may not oversee the fact that education is more effective than obligation. Being rebellious is a very common characteristic of the adolescence and by way of obligation (e.g. imposing smoking bans or forcing one to quit), the results might be reverse.

\section{References}

American Cancer Society. (2006). Global smoking epidemic. Retrieved 28 February, 2006, from http://www.cancer.org

Berkow, R., Beers, M., \& Fletcher (2000). The Merck manual of medical information: A West Point. PA: Merck and Company, Inc.

Burns, D., \& Pierce, J. P. (1997). Tobacco use in California. Sacramento, CA: California Department of Health Services.

Centers for Disease Control and Prevention. (2000). Selected cigarette smoking initiation and quitting behaviors among high school students, Mortal Wkly Rep MMWR Morb. United States. 
Costa, P. T., \& McCrae, R. R. (1992). Professional manual: Revised NEO personality inventory (NEO-PI-R) and NEO five-factor inventory (NEO-FFI). Odessa, FL: Psychological Assessment Resources.

Deborah, S. (2006). Predictors of cigarette smoking in adolescents with Asthma. PhD Thesis, Ohio University.

Diane, V., Ebert, S., \& Ngamvitroj, A. (2005). Factors related to cigarette smoking initiation and use among college students. Tobbaco Induced Diseases, 3, 27-40. http://dx.doi.org/10.1186/1617-9625-3-1-27

Ebert, S., Tucker, D., \& Roth, D. (2002). Psychological resistance factors as predictors of general health status and physical symptom reporting. Psychology, Health, \& Medicine, 7(3), 363-375. http://dx.doi.org/10.1080/1354 8500220139449

Eftekhari, M., Nassr, M., \& Sallehi, M. (2007). Prevalence of cigarette smoking in Tehran: A household study. Iranian Journal of Psychiatry and Behavioral Sciences, 1, 33-37.

Ehrhart, I. (2005). Alcohol expectancies and self-efficacy as moderators of social anxiety and alcohol use among college students. Virginia Polytechnic Institute and State University.

Erdfelder, E., Faul, F., \& Buchner, A. (1996). G-power: A general power analysis program. Behavior Research Methods, Instruments \& Computers, 28(1), 1-11. http://dx.doi.org/10.3758/BF03203630

Etter, J., Bergman, M., Humair, J., \& Perneger, T. (2000). Development and validation of a scale measuring self-efficacy of current and former smokers. Addiction, 95, 901-913. http://dx.doi.org/10.1046/j.1360-0443. 2000.9569017.x

Fagan, P., Eisenberg, M., Frazier, L., Stooddard, A., Avrunin, J., \& Sorensen, G. (2003). Employed adolescents and beliefs about self-efficacy to avoid smoking. Addictive Behaviors, 28(4), 613-626. http://dx.doi.org/10.1016/S0306-4603(02)00227-7

Hair, J. F., Black, W. C., Babin, B. J., Anderson, R. E., \& Tatham, R. L. (2006). Multivariate data analysis (6th Ed.). Upper Saddle river NJ: Prentice Hall.

Hair, J., Black, J., Babin, B., \& Anderson, R. (2010). Multivariate data analysis (7th Ed.). New Jersey: Practice Hall.

Hames, K., \& Parker, J. (2008). Personality and social differences of cigarette smoking among college students. Addiction, 1, 8-12.

Hiemstra, M., Otton, R., De Leeuw, R., Schayck, O., \& Engels, R. (2011). The changing role of self-efficacy in adolescent smoking initiation: A 4-year longitudinal study. Journal of adolescent health, 47(6), 597-603. http://dx.doi.org/10.1016/j.jadohealth.2010.09.011

Junger, M., Stroebe, W., \& Laan, A. (2001). Delinquency, health behaviour and health. British Journal of Health Psychology, 2, 103-120. http://dx.doi.org/10.1348/135910701169098

Kelishadi, R., Ardalan, G., \& Gheiratmand, R. (2006). Smoking behavior and its influencing factors in a national-representative sample of Iranian adolescents. Prevention Medicine, 42(6), 423-426. http://dx.doi.org/10.1016/j.ypmed.2006.03.001

Miller, S. (2009). Examining personality and college student risk-taking. Kent State University, Kent.

Mohammadpoor, A., Fakhari, A., Rostami, F., \& Pourafkary, N. (2007). Cigarette smoking among Iranian adolescents. Iranian Journal of Psychiatry and Behavioral Sceinces, 1(1), 30-35.

Nakhaee, N., \& Divsalar, K. (2009). Prevalence of factors associated with cigarette smoking among university students: A Study from Iran. Asia-Pacific Journal of Public Health, 76, 34-38.

Nichols, A. (2006). The influence of a school-based substance abuse prevention program reducing smoking among sixth grade African American students in Louisiana. University of California, Los Angeles.

Poorasl, A., Fakhari, A., \& Shamsipour, M. (2011). Transitions between the stages of smoking in Iranian adolescents. Science Direct, 52, 136-138.

Pouresmlami, M. (2008). Assessment of Beliefs about cigaratte smoking in middle school in Tehran. Univercity of Medical Sciences, Iran.

Rozi, S., Butt, Z., \& Akhtar, S. (2007). Demographic influences associated with current smoking status of collage students in Karachi, Pkistan. BMC Public Health, 7, 312-320. http://dx.doi.org/10.1186/1471-2458-7-312

Sarafzade, N., Boshtam, M., \& Tafazoli, F. (2004). Tobacco use among Iranian men, women and adolescents. European Journal of Pubmic Health, 14, 76-78. http://dx.doi.org/10.1093/eurpub/14.1.76 
Sterling, K., Diamond, P., Mullen, P., Pallonen, U., Ford, K., \& McAlister, A. (2007). Smoking-related self-efficacy, beliefs, and intention: assessing factorial validity and structural relationships in 9th-12th grade current smokers in Texas. Journal of Addictive Behaviors, 32, 1863-1876. http://dx.doi.org/10.1016/j.addbeh.2006.12.018

Taioli, E., \& Wynder, E. L. (1991). Effect of the age at which smoking begins on frequency of smoking in adulthood. New Engl J Med, 325, 968-969. http://dx.doi.org/10.1056/NEJM199109263251318

Terracciano, A., Lockenhoff, C., Crum, R., Bienvenu, J., \& Costa, P. (2008). Five-factor model personality profiles of drug users. BMC Psychiatry, 8(22), 1-10.

Torres, A., \& Pritchard, M. (2005). Personality characteristics as predictors of health risk behaviors. Boise State University, United States of America.

Von, D., Ebert, S., Ngamvitroj, A., Park, N., \& kang, D. (2005). Factors related to cigarette smoking initiation and use among college students. Tobbaco Induced Disease, 1, 27-40. http://dx.doi.org/10.1186/1617-9625$3-1-27$

World Health Organization. (2008). Tobacco key facts. Retrieved 11 May, 2008, from http://www.who/int/topics/tobacco/facts/en/index.html

Zargar, Y., \& Ghaffari, M. (2009). Simple and multiple relationships between Big-Five personality dimensions and addiction in University Students. Iranian Journal of Public Health, 38(3), 113-117.

Ziaaddini, M., Meymandi, M., \& Zarezadeh, A. (2007). The prevalence and motivation of cigarette smoking among Kerman high school students. Iranian Journal of Psychiatry, 2, 41-45.

\section{Appendix A}

Table 2. The Result of Personality Traits CFA Model

\begin{tabular}{|c|c|c|c|c|}
\hline Variables/dimensions & Items & $\begin{array}{l}\text { Standardized } \\
\text { Factor loading }\end{array}$ & $\begin{array}{l}\text { Average Variance Extracted } \\
\text { (AVE) }\end{array}$ & $\begin{array}{l}\text { Construct Reliability } \\
\text { (CR) }\end{array}$ \\
\hline \multirow[t]{12}{*}{ Extraversion } & P.T.Extra2 & .633 & \multirow[t]{12}{*}{.50} & \multirow[t]{12}{*}{.92} \\
\hline & P.T.Extra7 & .732 & & \\
\hline & P.T.Extra12 & .749 & & \\
\hline & P.T.Extra17 & .647 & & \\
\hline & P.T.Extra22 & .721 & & \\
\hline & P.T.Extra27 & .725 & & \\
\hline & P.T.Extra32 & .711 & & \\
\hline & P.T.Extra37 & .682 & & \\
\hline & P.T.Extra42 & .742 & & \\
\hline & P.T.Extra47 & .643 & & \\
\hline & P.T.Extra52 & .680 & & \\
\hline & P.T.Extra57 & .696 & & \\
\hline \multirow[t]{12}{*}{ Agreeableness } & P.T.Agree4 & .697 & \multirow[t]{12}{*}{.54} & \multirow[t]{12}{*}{94.} \\
\hline & P.T.Agree9 & .748 & & \\
\hline & P.T.Agree14 & .799 & & \\
\hline & P.T.Agree19 & .746 & & \\
\hline & P.T.Agree24 & .743 & & \\
\hline & P.T.Agree29 & .706 & & \\
\hline & P.T.Agree34 & .776 & & \\
\hline & P.T.Agree39 & .731 & & \\
\hline & P.T.Agree44 & .781 & & \\
\hline & P.T.Agree49 & .786 & & \\
\hline & P.T.Agree54 & .767 & & \\
\hline & P.T.Agree59 & .674 & & \\
\hline
\end{tabular}




\begin{tabular}{|c|c|c|c|c|}
\hline \multirow[t]{12}{*}{ Consciousness } & P.T.Con5 & .783 & .58 & .94 \\
\hline & P.T.Con10 & .738 & & \\
\hline & P.T.Con15 & .757 & & \\
\hline & P.T.Con20 & .799 & & \\
\hline & P.T.Con25 & .771 & & \\
\hline & P.T.Con30 & .691 & & \\
\hline & P.T.Con35 & .792 & & \\
\hline & P.T.Con40 & .810 & & \\
\hline & P.T.Con45 & .770 & & \\
\hline & P.T.Con50 & .811 & & \\
\hline & P.T.Con55 & .776 & & \\
\hline & P.T.Con60 & .721 & & \\
\hline \multirow[t]{12}{*}{ Neuroticism } & P.T.Neo1 & .705 & .48 & .91 \\
\hline & P.T.Neu6 & 699 & & \\
\hline & P.T.Neu11 & .697 & & \\
\hline & P.T.Neu16 & .687 & & \\
\hline & P.T.Neu21 & .693 & & \\
\hline & P.T.Neu26 & .671 & & \\
\hline & P.T.Neu31 & .675 & & \\
\hline & P.T.Neu36 & .720 & & \\
\hline & P.T.Neu41 & .627 & & \\
\hline & P.T.Neu46 & .705 & & \\
\hline & P.T.Neu51 & .638 & & \\
\hline & P.T.Neu56 & .692 & & \\
\hline \multirow[t]{12}{*}{ Openness } & P.T.Open3 & .723 & .50 & .92 \\
\hline & P.T.Open8 & .707 & & \\
\hline & P.T.Open 13 & .724 & & \\
\hline & P.T.Open 18 & .745 & & \\
\hline & P.T.Open23 & .738 & & \\
\hline & P.T.Open 28 & .623 & & \\
\hline & P.T.Open33 & .761 & & \\
\hline & P.T.Open38 & .706 & & \\
\hline & P.T.Open 43 & .723 & & \\
\hline & P.T.Open 48 & .746 & & \\
\hline & P.T.Open53 & .629 & & \\
\hline & P.T.Open58 & .684 & & \\
\hline
\end{tabular}

\section{Copyrights}

Copyright for this article is retained by the author(s), with first publication rights granted to the journal.

This is an open-access article distributed under the terms and conditions of the Creative Commons Attribution license (http://creativecommons.org/licenses/by/3.0/). 